\title{
Trypsin Action on the Growth of Sendai Virus in Tissue Culture Cells
}

\author{
III. Structural Difference of Sendai Viruses Grown in Eggs and Tissue \\ Culture Cells
}

\author{
MORIO HOMMA AND MASANOBU OHUCHI \\ Department of Bacteriology, Yamagata University School of Medicine, Yamagata, and Department of \\ Bacteriology, Tohoku University School of Medicine, Sendai, Japan
}

Received for publication 16 July 1973

\begin{abstract}
Polypeptides of egg-borne Sendai virus (egg Sendai), which is biologically active on the basis of criteria of the infectivity for $\mathrm{L}$ cells and of hemolytic and cell fusion activities, were compared by polyacrylamide gel electrophoresis with those of L cell-borne (L Sendai) and HeLa cell-borne Sendai (HeLa Sendai) viruses, which are judged biologically inactive by the above criteria. Densitometer profiles on the stained gels of egg Sendai resolved six polypeptides (virion protein [VP] 1 to VP6), in which VP2 and VP4 were identified as glycoproteins by PAS stain. Comparative electropherograms of both L Sendai and HeLa Sendai revealed that there were significantly larger amounts in the VP2 region of these viruses but VP4 was present only in greatly reduced amounts as compared to egg Sendai. It was also found that VP2 of L Sendai and HeLa Sendai consisted of two components, VP2a and VP2b, but the one of egg Sendai consisted of only VP2a. A mild trypsin treatment which converts both L Sendai and HeLa Sendai to a biologically active form selectively removed VP2b from these viruses and increased concomitantly the amounts of materials in the VP4 region. The same treatment of egg Sendai affected neither its biological activities nor its electropherogram. Consequently, gross polypeptide profiles on the stained gels of L Sendai and HeLa Sendai after trypsin treatment became favorably comparable to that of egg Sendai. Electrophoresis of labeled L Sendai and HeLa Sendai with a ${ }^{3} \mathrm{H}$-amino acids mixture and ${ }^{14} \mathrm{C}$-glucosamine resolved at least three glycoproteins, GP1, GP2, and GP3, each corresponding to VP2a, VP2b, and VP4, respectively. The trypsin treatment of these viruses removed almost all the radioactivity of GP2 and simultaneously increased the radioactive counts of GP3 and raised small amounts of rapidly moving heterogeneous glycoprotein, GP4. A possible relationship between the biological modification and the above characteristic polypeptide patterns of Sendai virus was discussed.
\end{abstract}

Evidence of modifications of paramyxoviruses by host cells in chemical composition $(18,19)$, physical properties $(5,8,29)$ and biological activities $(4,8-11,14,22,30)$ has been accumulated. With the advent of polyacrylamide gel electrophoresis $(21,27)$, characterization of structural proteins of paramyxoviruses has progressed. However, little information is available concerning the biological modifications of these viruses on the basis of the chemical term.

In previous papers, it was described that $\mathrm{L}$ cell-borne Sendai virus (L Sendai) exhibited less biological activity for L-cell infectivity, hemolysis, and cell fusion as compared to eggborne Sendai virus (egg Sendai). It was also found that a mild treatment of L Sendai with trypsin remarkably enhanced all of the above activities (8-10). One of the authors (M. H.) has inferred from these observations the presence of an inhibitory substance on the surface of $L$ Sendai.

The present study was undertaken to explain the biological defectiveness of $L$ Sendai virus and that of HeLa cell-borne Sendai virus (HeLa Sendai), which also exhibits the biological defectiveness in characteristic polypeptide patterns on polyacrylamide gel electrophoresis. The results seem to provide a better understanding of the biological modification of Sendai virus on the structural basis and to support the previously proposed working hypothesis of the "masking substance" $(8,9)$. The results will 
also be helpful for interpreting the electropherograms of Sendai virus on polyacrylamide gel electrophoresis.

\section{MATERIALS AND METHODS}

Cells. Monolayer cultures of $\mathrm{L}$ cells and a subline of HeLa S3 cells (15) were grown in petri dishes as described previously (8). For virus infection, a maintenance solution (MS) which consisted of Eagle minimum essential medium with $1 \mathrm{mmol}$ of L-serine (15) and $2 \%$ heated horse serum was substituted for the growth medium.

Virus growth. The Fushimi strain of Sendai virus was used. Seed stocks were grown in allantoic cavities of 10-day-old embryonated hen eggs from a $10^{\circ}$ dilution of seed virus, and the allantoic fluid was harvested after incubation for $72 \mathrm{~h}$ at $36 \mathrm{C}$ (egg Sendai). L Sendai and HeLa Sendai were prepared by inoculating the monolayer cultures of these cells with egg Sendai at an input multiplicity of 10 mean egg infective doses $\left(\right.$ EID $_{50}$ ) per cell. After adsorption for 1 $\mathrm{h}$ at $36 \mathrm{C}$, the infected cultures were washed and the medium was replaced with fresh MS. The virus was collected from the medium $48 \mathrm{~h}$ postinfection. To label virus, $5 \mu \mathrm{Ci}$ of a ${ }^{3} \mathrm{H}$-amino acids mixture per $\mathrm{ml}$ (New England Nuclear Co., average specific activity $23 \mathrm{Ci} / \mathrm{mmol}$ ) or $1 \mu \mathrm{Ci}$ of ${ }^{14} \mathrm{C}$-D-glucosamine per $\mathrm{ml}$ (Daiichi Pure Chemical Co., specific activity 57.5 $\mathrm{mCi} / \mathrm{mmol}$ ) was added to MS after virus adsorption.

Preparation of chicken red blood cell ghosts. Preparation of chicken red blood cell ghosts essentially followed the method of Amano (Y. Amano, personal communication). A $50-\mathrm{ml}$ amount of heparinized chicken blood specimens was collected. Erythrocytes were washed three times with phosphate-buffered saline (PBS), $\mathrm{pH} 7.2$, and hemolyzed in $500 \mathrm{ml}$ of $0.0004 \%$ chilled acetic acid with stirring for $60 \mathrm{~min}$ at $0 \mathrm{C}$. The ghosts were then washed several times in a $0.001 \mathrm{M}$ chilled acetate buffer $(\mathrm{pH} 5.0)$ by centrifugation at $1,000 \times g$ for 5 min until the supernatant fluid was decolored. The same washing procedure was repeated by using chilled PBS, and the ghost suspension was left overnight at $4 \mathrm{C}$. After the last washing at $700 \times g$ for $2 \mathrm{~min}$, the ghosts were suspended in PBS containing $0.5 \%$ sodium azide, using 4 volumes of PBS for 1 volume of the sediment, and stored at $4 \mathrm{C}$ for more than 2 months. Upon use, a portion was washed twice in PBS by the aid of centrifugation at $700 \times g$ for 2 min.

Virus purification. All labeled and unlabeled viruses were sedimented by differential centrifugations at $3,300 \times g$ for $15 \mathrm{~min}$ and $65,000 \times g$ for $30 \mathrm{~min}$, and the virus pellets were suspended in PBS. One volume of the packed chicken red blood cell ghosts were added to 4 volumes of the virus suspension containing 4,000 hemagglutinating units (HAU) per $\mathrm{ml}$, and virus adsorption was made for 60 min at $0 \mathrm{C}$ by stirring. The ghosts were then washed three times by adding 10 volumes of chilled PBS and centrifuging at $1,000 \times g$ for $2 \mathrm{~min}$. Virus elution was made by suspending the virus in 10 volumes of PBS for $30 \mathrm{~min}$ at $36 \mathrm{C}$. After removing the ghosts at 1,500 $\times g$ for $10 \mathrm{~min}$, this elution process was repeated. The resulting supernatant fluids were pooled and again subjected to the differential centrifugations as described above, and the virus pellets were finally taken up by PBS. This procedure finally recovered more than $50 \%$ of the original virus HA.

Treatment of Sendai virus with trypsin. Viruses were treated with crystalline trypsin, and the enzymatic action was immediately halted by soybean trypsin inhibitor as described previously (8), except that a larger volume of each reagent was applied in proportion to the increase of the volume of virus samples to be tested. The condition which resulted from the trypsin treatment in the present experiment was the same with all of the given viruses, under which the maximal restoration of the infectivity for $L$ cells (8), hemolysis (9) and cell fusion (10) of L Sendai was known to be induced $(0.0004 \%$ for 6 min at $36 \mathrm{C})$. Before treatment, the samples were diluted by PBS to contain 500 to $1,000 \mathrm{HAU} / \mathrm{ml}$.

Virus assay. The infectivity of all of the Sendai viruses recovered from different hosts was determined by the immunofluorescent cell-counting technique on cover-slip cultures of $L$ cells $(8,16)$. Measurement of hemolysis was made by the method as described previously (9).

Polyacrylamide gel electrophoresis. A portion of virus samples from both trypsin-treated and control groups, usually containing 1,500 HAU in total, was centrifuged at $65,000 \times g$ for $30 \mathrm{~min}$, and the pellet was resuspended in $0.08 \mathrm{ml}$ of PBS. Each sample was heated at $100 \mathrm{C}$ for $2 \mathrm{~min}$ in the presence of $1 \%$ sodium dodecyl sulfate (SDS) and 1\% 2-mercaptoethanol $(21,28)$, to which then were added $10 \%$ glycerol and $0.01 \%$ tetrabromophenol-sulfonphthalein as a marker dye. A whole amount was layered on a gel column of $6 \mathrm{~cm}$ length and $6 \mathrm{~mm}$ diameter. Preparation of gels essentially followed the method of Maizel (21). A solution containing $7.5 \%$ acrylamide, $0.2 \%$ $N, N^{\prime}$-methylenebisacrylamide, $\quad 0.1 \mathrm{M}$ sodium phosphate buffer $(\mathrm{pH} 7.2)$, and $0.1 \%$ SDS was polymerized by addition of $0.075 \%$ ammonium persulfate and $0.05 \% N, N, N^{\prime}, N^{\prime}$-tetramethylethylenediamine. All gels were prerun for $2 \mathrm{~h}$ prior to use. Electrophoresis of samples was performed at $5 \mathrm{~mA}$ per gel for $7 \mathrm{~h}$ at room temperature. At the end of the run, gels were removed from the tubes, fixed, and stained either with Coomassie brilliant blue R-250 for proteins (21) or with the periodic acid-Schiff technique (PAS) for sugars (31). The stained gels with Coomassie blue were scanned at $560 \mathrm{~nm}$ by a linear transport of Gilford spectrophotometer 2400-S. Gels containing radioactive materials were immediately frozen and sliced with a self-made gel slicer into $0.7-\mathrm{mm}$ thickness. Each disk was collected into a scintillation vial and incubated with $0.5 \mathrm{ml}$ of $1 \mathrm{~N} \mathrm{NaOH}$ at room temperature overnight. A $10-\mathrm{ml}$ amount of scintillator consisting of 3 parts nonyphenol polyethoxyethanol (Nonion, Japan), 7 parts toluene, and $4 \mathrm{~g}$ of 2,5-diphenyloxazole per liter was added and then mixed with $0.5 \mathrm{ml}$ of $2 \mathrm{~N} \mathrm{HCl}$ (M. Kawakami, R. Majima, and K. Shimura, personal communication). The radioactivity was measured in a Packard liquid scintillation counter. 


\section{RESULTS}

Biological properties of HeLa Sendai. Preliminary studies showed that the biological modification of Sendai virus as observed with L Sendai was not merely confined to this particular virus-cell system but could be extended to the viruses grown in other various tissue culture cells such as HeLa and FL cells. HeLa Sendai grossly lacked in hemolytic and cell fusion activities and in the infectivity for $\mathrm{L}$ cells as well as for HeLa cells, and these activities were maximally restored by the same trypsin treatment as used for L Sendai (8-10). Moreover, every preparation of HeLa Sendai was shown to have a more advanced degree of the biological defectiveness than L Sendai (see Table 1). Judging from these observations, the defective properties of HeLa Sendai are also attributable to host-controlled modification and fall under the description of $\mathrm{L}$ Sendai.

Polyacrylamide gel electrophoresis of unlabeled Sendai viruses. Figure 1a shows the densitometer profile of egg Sendai subjected to polyacrylamide gel electrophoresis and also the gels stained with either Coomassie blue or with PAS.

It appears that egg Sendai consists of six viral proteins (VP). On the stained gels, 4 distinctly (VP2, VP3, VP4, and VP6), 1 lightly (VP1), and 1 faintly (VP5) stained bands are seen, the results showing a good correspondence to those obtained by other workers $(12,28)$. Two polypeptides, VP2 and VP4, are identified as glycoproteins by PAS stain. VP3, the most prominent protein, is not a glycoprotein on the basis of negative staining with PAS and is presumed to be the nucleocapsid protein $(3,24)$.

The electrophoretic pattern of L Sendai is illustrated in Fig. 2a. Six proteins as observed

TABLE 1. Enhancement of the biological activities of Sendai viruses grown in various hosts by trypsin treatment $^{a}$

\begin{tabular}{l|c|c|c|c}
\hline \multirow{2}{*}{ Viruses } & \multicolumn{2}{|c|}{$\begin{array}{c}\text { Hemolysis } \\
\left(\mathrm{OD}^{\circ} \text { at } 575 \mathrm{~nm}\right)\end{array}$} & \multicolumn{2}{c}{$\begin{array}{c}\text { Infectivity } \\
\text { (CIUc/ml) }\end{array}$} \\
\cline { 2 - 5 } & $\begin{array}{c}\text { Before } \\
\text { trypsin }\end{array}$ & $\begin{array}{c}\text { After } \\
\text { trypsin }\end{array}$ & $\begin{array}{c}\text { Before } \\
\text { trypsin }\end{array}$ & $\begin{array}{c}\text { After } \\
\text { trypsin }\end{array}$ \\
\hline Egg Sendai & 1.315 & 1.287 & $7.0 \times 10^{8}$ & $7.2 \times 10^{8}$ \\
L Sendai & 0.235 & 0.945 & $9.0 \times 10^{\circ}$ & $1.1 \times 10^{8}$ \\
HeLa Sendai & 0.015 & 0.923 & $1.5 \times 10^{\circ}$ & $2.3 \times 10^{8}$ \\
\hline
\end{tabular}

a Each purified virus sample in PBS containing 500 hemagglutinin units per $\mathrm{ml}$ was divided into two groups. One-half was treated with trypsin at $0.0004 \%$ for 6 min at $36 \mathrm{C}$ and the other half was mock treated with PBS. Measurements of the hemolytic activity and the infectivity for $L$ cells were as described $(8,16)$.

- Optical density.

c Cell infectivity unit (16).

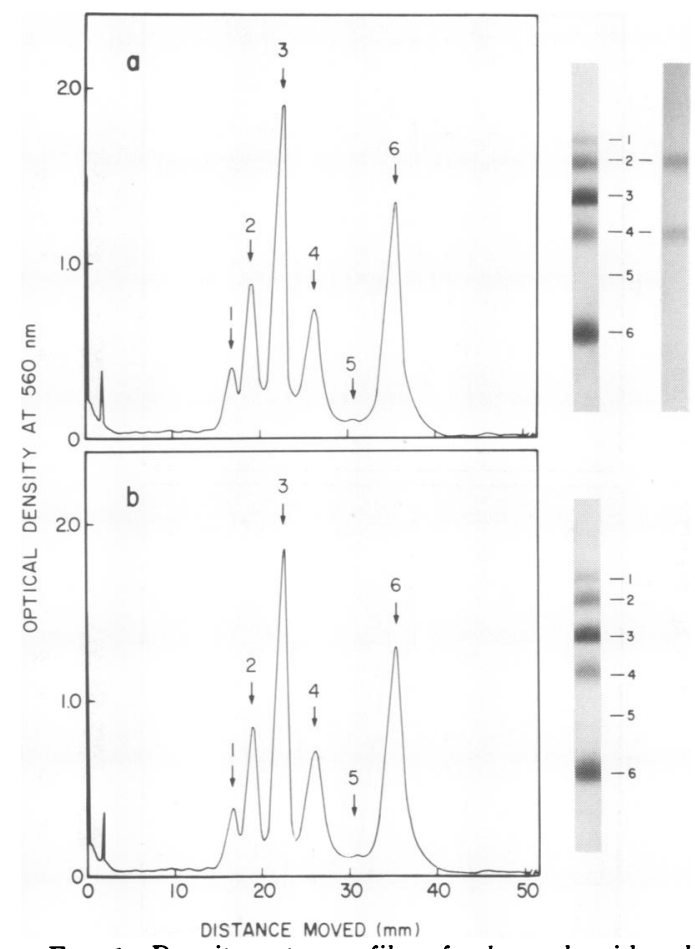

Fig. 1. Densitometer profiles of polyacrylamide gel electrophoresis patterns of egg Sendai and the photographs of the gels stained with Coomassie blue and PAS. Portions of egg Sendai both nontreated $(a)$ and treated with trypsin (b) were dissolved in $1 \%$ SDS with 1\% 2-mercaptoethanol, and subjected to electrophoresis in 6-cm-long gels containing $7.5 \%$ acrylamide and $0.1 \%$ SDS for $7 \mathrm{~h}$ at $5 \mathrm{~mA}$ per gel. Gels were stained with Coomassie blue, and optical density scannings were read at $560 \mathrm{~nm}$. Glycoproteins were identified by PAS staining. In this and all subsequent electropherograms, the anode is on the right.

with egg Sendai are readily detected on the gel stained with Coomassie blue and each of them migrates almost identically with the corresponding proteins of egg Sendai. It was repeatedly found, however, that VP2 is larger in amount and distributes rather broadly towards VP3 when compared with that of egg Sendai; VP4, on the contrary, is significantly less in amount. Sometimes, but less frequently, a shoulder was found in the VP2 region in the absorption profile of the stained gel. That VP2 of L Sendai and HeLa Sendai consists of two components, VP2a and VP2b, will be ascertained by the analysis of radioisotopically labeled viruses in the forthcoming experiments (see Fig. 4a and 5a). These characteristic features became more pronounced when HeLa Sendai, having a more advanced degree of the biological defectiveness, was used instead of $L$ 


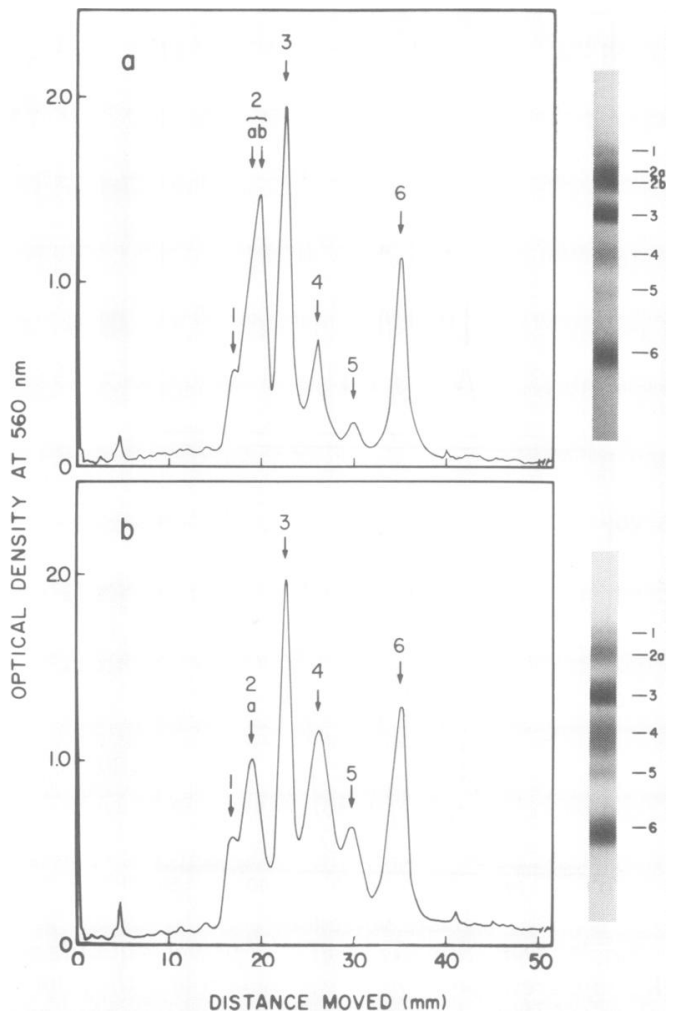

Fig. 2. Densitometer profiles of polyacrylamide gel electrophoresis patterns of $L$ Sendai and the photograph of the gel stained with Coomassie blue. Portions of $L$ Sendai both nontreated $(a)$ and treated with trypsin (b) were subjected to electrophoresis as described in Fig. 1.

Sendai (Fig. 3a). A protein, VP2b, which migrates quite closely to, but slightly faster than, VP2a is present in larger amounts. This protein is usually detectable in the absorption profile of the stained gel either as a separate protein or as a shoulder overlapping VP2a. VP4 is present consistently, but in extremely small amounts. A shoulder overlapping VP6 is inevitably found between VP5 and VP6. This, however, has never been detected with egg Sendai and L Sendai (see Fig. 5a and 5b).

Electrophoretic pattern of Sendai virus after trypsin treatment. The results in the foregoing experiments have clearly revealed a difference in the patterns of the polypeptides between egg Sendai and the remaining two viruses, L Sendai and HeLa Sendai. It was of interest, therefore, to know how this difference relates to the biological defectiveness of the latter two viruses. As mentioned already, a treatment of both L Sendai and HeLa Sendai with trypsin under a certain condition induced the maximal restoration of the biological activi- ties whereas the same treatment did not affect those of egg Sendai (Table 1). If the altered polypeptide patterns of both $\mathrm{L}$ Sendai and HeLa Sendai are associated specifically with their biological defectiveness, it would be expected that the polypeptide patterns of these viruses after restoration of their biological activities by the trypsin treatment might differ from those of the original defective viruses at some specific sites, whereas the pattern of egg Sendai might remain unchanged by the same trypsin treatment.

Each portion of the respective viruses which had been treated with trypsin as described in Table 1 was subjected to polyacrylamide gel electrophoresis. Figure 1b shows the polypeptide pattern of egg Sendai after such treatment. Obviously none of the change is observed. This indicates either that egg Sendai is resistant to this treatment or that egg Sendai has no site sensitive to this particular treatment. The same treatment of L Sendai with trypsin, however, resulted in considerable changes in its protein pattern (Fig. 2b). The amount of materials at

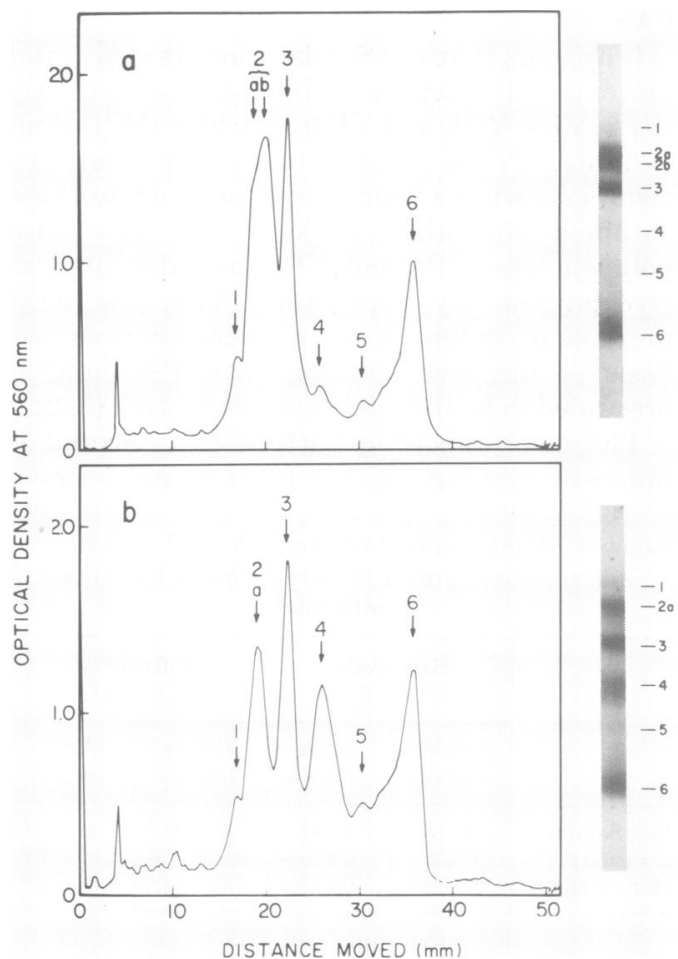

Fig. 3. Densitometer profiles of polyacrylamide gel electrophoresis patterns of $\mathrm{HeLa}$ Sendai and the photograph of the gel stained with Coomassie blue. Portions of HeLa Sendai both nontreated (a) and treated with trypsin (b) were subjected to electrophoresis as described in Fig. 1. 
the VP2 region is reduced significantly, and the band becomes sharper due to missing the materials at VP2b. On the contrary, the amounts of VP4 increased and the resulting overall pattern now can favorably be compared with that of egg Sendai. No significant changes are detectable in the other polypeptide regions. The treatment of HeLa Sendai with trypsin yields essentially the same kind of changes as in the case of $L$ Sendai. As shown in Fig. 3, VP2b is not detectable and, as compensation for this, the amount of VP4 is increased greatly (Fig. 3b). No other changes are noticed. As with the case of L Sendai, the resulting pattern of HeLa Sendai after trypsin treatment has become comparable to that of egg Sendai.

Analysis of labeled Sendai viruses on polyacrylamide gel electrophoresis. To obtain more detailed information on the polypeptide patterns of $L$ Sendai and HeLa Sendai, the analysis was made with radioactively labeled viruses. Portions of $\mathrm{L}$ Sendai grown in the presence of either ${ }^{3} \mathrm{H}$-amino acids mixture or ${ }^{14} \mathrm{C}$-glucosamine were purified separately and combined. The mixture was divided into two portions. One-half was treated with trypsin and the other half remained untreated. After centrifugation at $65,000 \times g$ for $30 \mathrm{~min}$, each pellet was suspended in PBS and subjected to gel electrophoresis. The same procedure applied to the analysis of $\mathrm{HeI}$ a Sendai.

The radioactive profile of the nontreated $L$ Sendai is shown in Fig. 4a. The overall profile is very close to that reported by Content and Duesberg (3) using Sendai virus grown in MDBK cells. The most prominent protein, designated NP, is apparently freed from ${ }^{14} \mathrm{C}$ label and again identified as nucleocapsid protein $(3,24)$. Evidently, VP2 is resolved into two components of glycoprotein, GP1 and GP2. VP4 is readily identified as glycoprotein (GP3). It has consistently been observed that GP2 is higher in amount than GP3, although this relative ratio varies from one preparation to another. The most striking changes are detected in both GP2 and GP3 regions after trypsin treatment. This particular treatment selectively removes both ${ }^{14} \mathrm{C}$ and ${ }^{3} \mathrm{H}$ counts in GP2 and simultaneously increases the counts in GP3 region. Another minor change is always noticed in the fast-moving fraction, GP4, where small amounts of radioactive counts migrate heterogeneously (Fig. 4b).

The radioactive patterns of HeLa Sendai before and after exposure to trypsin are shown in Fig. 5. As with the case of L Sendai, in nontreated HeLa Sendai, GP1 and GP2 are resolved and the amounts of radioactive counts of GP2 are very large. In contrast, the amounts of GP3 are extremely small (Fig. 5a). After exposure to trypsin, both kinds of the radioactive materials in GP2 are reduced to undetectable level, leaving GP1 as an isolated single peak (Fig. 5b). Again the amounts of radioactive counts in GP3 region are increased considerably and those in GP4 region are increased slightly. In every preparation of HeLa Sendai, a peak with ${ }^{14} \mathrm{C}$ label is found between VP5 and VP6, but the presence of ${ }^{3} \mathrm{H}$ label in this fraction is questionable. It is clear from the results that this fraction is completely resistant to the trypsin treatment used in this experiment. Although we did not study this fraction further, it may not be specified by virus since it has never been found in the virus grown in the other cells, suggesting a kind of host-induced modification.

It should be emphasized that the above characteristic polypeptide patterns of both $\mathrm{L}$ Sendai and HeLa Sendai, once induced by the treatment with trypsin $(0.0004 \%)$ for $6 \mathrm{~min}$, were quite stable and durable for at least another $30 \mathrm{~min}$ of exposure (data not shown). In contrast, the higher concentration of trypsin $(0.02 \%)$ led to an immediate disruption of the patterns only after $6 \mathrm{~min}$ of exposure.

\section{DISCUSSION}

Egg Sendai has been shown by polyacrylamide gel electrophoresis to contain six polypeptides (VP1 to VP6) on the stained gel. Electropherograms of both L Sendai and HeLa Sendai have revealed differences from that of egg Sendai, showing that VP2 consists of two components, VP2a and VP2b, and VP4 is present either in greatly reduced amounts with L Sendai or in trace amounts with HeLa Sendai. The trypsin treatment which enhanced the biological activities of L Sendai and HeLa Sendai selectively removed VP2b and simultaneously resulted in the increase of VP4. The same treatment affected neither the biological activities nor the peptide patterns of egg Sendai. VP2 of egg Sendai contained only VP2a but not VP2b, and considerable amounts of VP4 were present consistently. Consequently, the peptide patterns of L Sendai and HeLa Sendai after trypsin treatment became favorably comparable to that of egg Sendai. Analysis of the labeled L Sendai and HeLa Sendai with ${ }^{3} \mathrm{H}$-amino acids mixture and ${ }^{14} \mathrm{C}$-glucosamine clearly resolved VP2a and VP2b, and these components as well as VP4 were shown to be glycoproteins corresponding to GP1, GP2, and GP3, respectively. Shimizu et al. (28) also found in the polypeptide analysis of egg-borne Sendai virus that the 


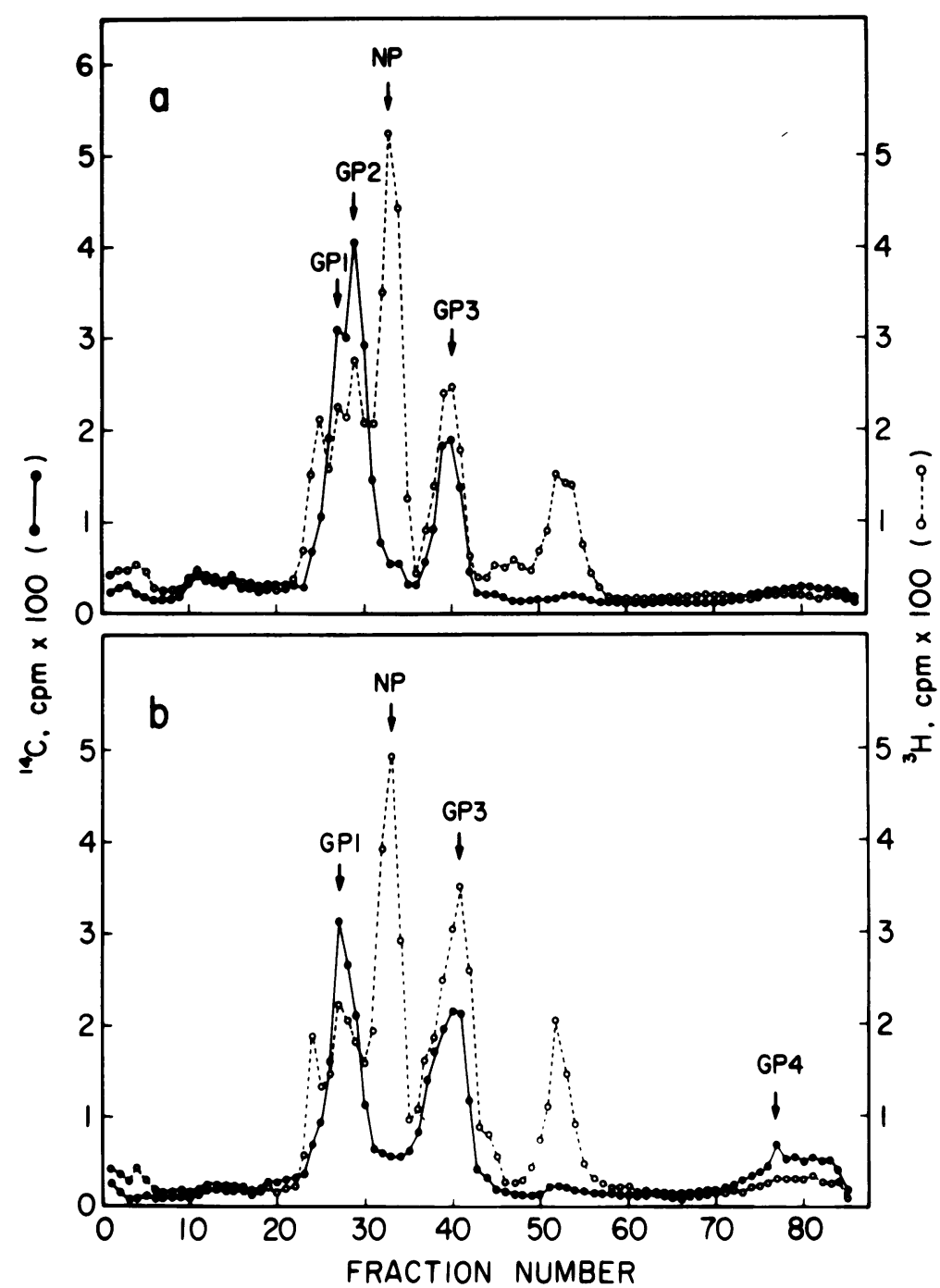

FIG. 4. Electrophoretic patterns of $L$ Sendai before and after treatment with trypsin. Portions of $L$ Sendai, each grown in $L$ cells in the presence of ${ }^{3} \mathrm{H}$-amino acids mixture $\left(\mathrm{O}_{----O}\right)$ and in the presence of ${ }^{14} \mathrm{C}$-glucosamine (-), were mixed, treated without $(a)$ or with trypsin $(b)$, and subjected to polyacrylamide gel electrophoresis as described in Fig. 1. Gels were sliced into $0.7 \mathrm{~mm}$ thickness. NP represents the nucleocapsid protein. In this and in Fig. 5, GP1, GP2 and GP3 correspond to $2 a, 2 b$, and 4, respectively, in Fig. 2 and 3.

fast-moving glycoprotein, P2 (GP3 of our designation), was present in relatively large amounts. Resolution of two slowly migrating glycoproteins (presumably corresponding to GP1 and GP2 of our designation) of Sendai virus grown in MDBK line of bovine kidney cells were shown independently by Content and Duesberg (3) and Mountcastle et al. (24), although the latter authors claimed that it was rather caused by overlapping of one of the glycoproteins. All of these data seem to be consistent with our present findings.
The altered polypeptide patterns of L Sendai and HeLa Sendai as compared to egg Sendai can not be directly related to their biological defectiveness and it may be argued that we are looking at coupled, but independent, phenomena. The following facts, however, should be noted. First, the trypsin treatment we used affected neither the biological activities nor the peptide pattern of egg Sendai. Secondly, the trypsin treatment at the given concentration induced the maximal enhancement of the biological activities of both $\mathrm{L}$ Sendai and HeLa 
Sendai only in the first few minutes and simultaneously resulted in loss of GP2, increase of GP3, and formation of GP4 of both viruses. The prolonged incubation for 30 min caused a slight decrease of the biological activities $(8,9)$ and practically no further change in the polypeptide patterns. These facts obviously indicate that this trypsin treatment is quite different in a qualitative sense from the one used by others to remove a certain structural component from the surface of Sendai virus (20), and also from the enzymatic treatments of the nucleocapsids which cleaved the larger subunit of the nucleocapsid protein to the smaller one $(1,2,23)$. Finally, HeLa Sendai which exhibits less defective activities than $\mathrm{L}$ Sendai showed a more advanced degree of the above structural alteration than did L Sendai. From these considerations, it seems rather likely to relate the observed alteration in the polypeptide pattern to the biological defectiveness.

In the previous papers of this series, one of the authors (M. H.) proposed the masking substance hypothesis on the basis of the observations that the reduced biological activities of $L$ Sendai were effectively unmasked by the trypsin treatment $(8,9)$. Although we have not isolated such a substance as a single entity, a certain portion (probably the carbohydrate portion) or a whole structure of GP2 seems to be the most likely candidate for such substance responsible for the masking of the biological

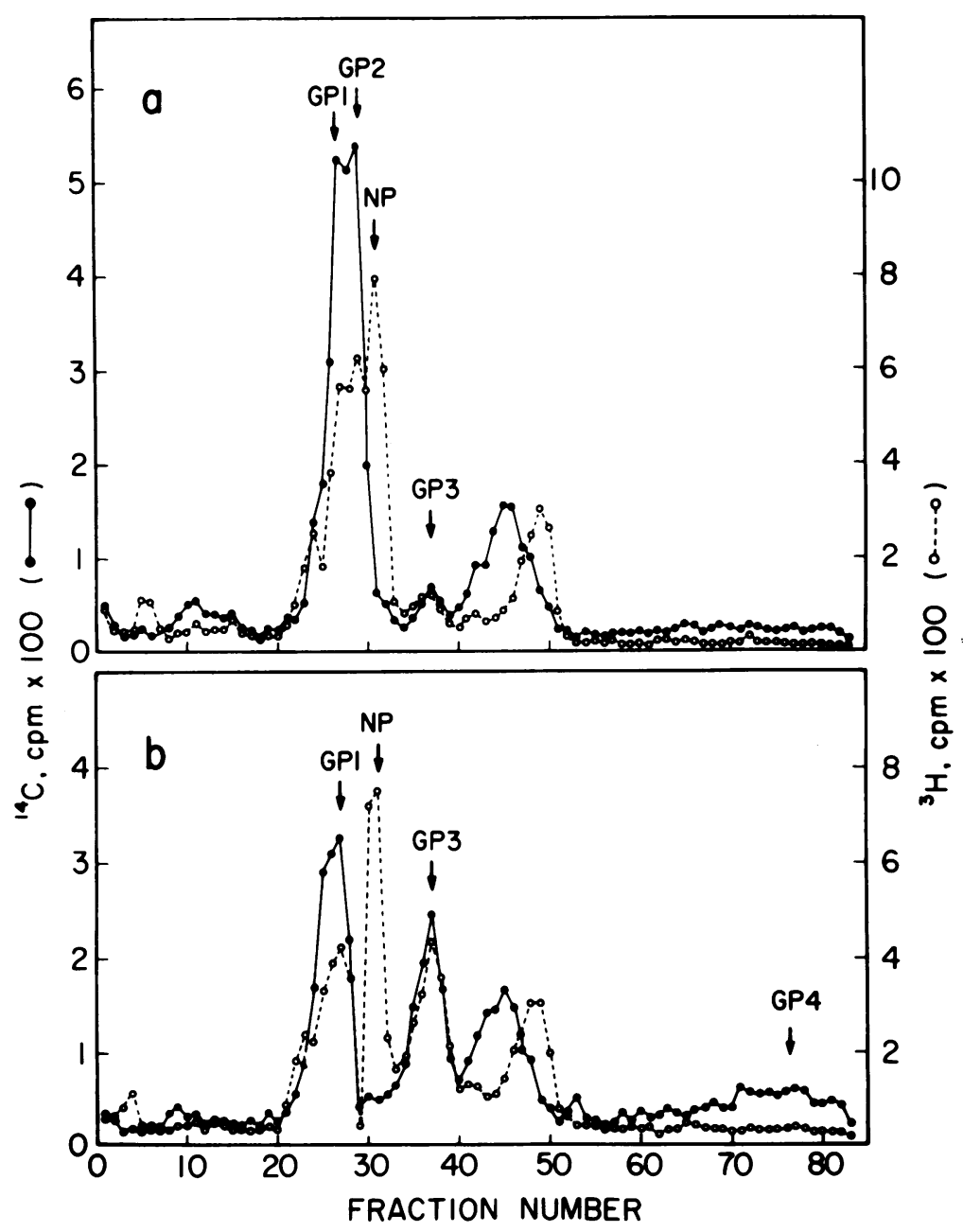

Fig. 5. Electrophoretic patterns of HeLa Sendai before and after treatment with trypsin. Portions of HeLa Sendai, each grown in $\mathrm{HeLa}$ cells in the presence of ${ }^{3} \mathrm{H}$-amino acids mixture (O- - - -O) and in the presence of ${ }^{14} \mathrm{C}$-glucosamine (-O), were mixed, treated without $(a)$ or with trypsin (b), and subjected to polyacrylamide gel electrophoresis as described in Fig. 1. 
activities of Sendai virus. The trypsin treatment may specifically cleave GP2 and convert it presumably to GP3 and GP4 and/or some other components which are liberated from the virion. The liberation of both the ${ }^{14} \mathrm{C}$ label and the ${ }^{3} \mathrm{H}$ label by this treatment from L Sendai and HeLa Sendai separately is usually less than $3 \%$ for each. Attempts at identifying the liberated materials on the polyacrylamide gel electrophoresis have been unsuccessful. A view that GP3 is a cleavage product of GP2 is likely because of the facts that the specific ratio of the radioactive counts of ${ }^{14} \mathrm{C}$ to ${ }^{3} \mathrm{H}$ of GP3 was not changed during the trypsin treatment of $\mathrm{L}$ Sendai and HeLa Sendai, even though the amounts of both kinds of counts were increased. If this is the case, GP3 must combine with a component with higher ${ }^{14} \mathrm{C}$ label to form GP2 since the specific ratio of ${ }^{14} \mathrm{C}$ to ${ }^{3} \mathrm{H}$ of GP2 was considerably higher than that of GP3. At present, we assume that GP4 is a putative candidate for such component because it arose only after trypsin treatment and had a higher specific ratio of ${ }^{14} \mathrm{C}$ to ${ }^{3} \mathrm{H}$. However, for more conclusive evidence, this is the subject of further study.

In the case of myxoviruses, the evidence seems to have been established that hemagglutinating and neuraminidase activities reside on different proteins (17). However, with paramyxoviruses, the relationship between these biological activities and the structural proteins has not been established. Although it has been reported that neuraminidase and hemagglutinating activities of Newcastle disease virus (NDV) $(6,13)$ and Sendai virus (20) reside on different proteins as with the case of myxoviruses, the recent reports on simian virus 5 (25) and NDV (26) as well as on Sendai virus (Tozawa et al., Virology, in press) do not support these findings but imply that hemagglutinating and neuraminidase activities of these viruses reside on a single glycoprotein. With regard to this point, it seems valuable to recall the fact from the present system that both hemagglutinating and neuraminidase activities of L Sendai and HeLa Sendai were never masked (7).

Tozawa et al. have also found in their polyacrylamide gel electrophoresis study of Sendai virus grown in calf kidney cells a glycoprotein which migrates very closely to, but faster than, a protein with which the blocking activity of hemagglutination inhibition and neuraminidase activity are associated, and this glycoprotein is in good accordance with our GP2 (Virology, in press).

Through the studies on the masking phenomenon in the present system, we noted that egg
Sendai is apparently resistant to the trypsin treatment. Two explanations for this might be possible. The first one is that the masking substance may not be synthesized in ovo and the eggs produce exclusively fully active Sendai virus. The alternative one is that egg Sendai in situ has the masking substance but there is an activator(s) like trypsin in ovo, probably in the allantoic fluids, and consequently one merely encounters the egg Sendai already activated by it. There is favorable evidence to support the latter possibility that incubation of $\mathrm{L}$ Sendai and HeLa Sendai in the allantoic fluids has converted both viruses to biologically active forms (M. Homma, manuscript in preparation).

It should be mentioned that, whenever structural studies are made on paramyxoviruses, modification of not only biological activity but also of their structure should be kept in mind. The present findings of the structural modification may be helpful for interpreting the electropherograms of paramyxoviruses, although our study has been limited to Sendai virus at present.

\section{ACKNOWLEDGMENTS}

We would like to thank $\mathrm{N}$. Ishida for interest and support. We are also grateful to $H$. Shinohara, $H$. Tozawa, and $K$. Shimizu for valuable discussions and criticism, and to $\mathrm{K}$. Tada for competent technical assistance.

This investigation was supported by a research grant from the Ministry of Education, Japan.

\section{LITERATURE CITED}

1. Bikel, I., and P. H. Duesberg. 1969. Proteins of Newcastle disease virus and of the viral nucleocapsid. J. Virol. 4:388-393.

2. Caliguiri, L. A., H. D. Klenk, and P. W. Choppin. 1969. The proteins of the parainfluenza virus SV5. I. Separation of virion polypeptides by polyacrylamide gel electrophoresis. Virology 39:460-466.

3. Content, J., and P. H. Duesberg. 1970. Electrophoretic distribution of the proteins and glycoproteins of influenza virus and Sendai virus. J. Virol. 6:707-716.

4. Drake, J. W., and P. A. Lay. 1962. Host-controlled variation in NDV. Virology 17:56-64.

5. Evans, M. J., and D. W. Kingsbury. 1969. Separation of Newcastle disease virus proteins by polyacrylamide gel electrophoresis. Virology 37:597-604.

6. Haslam, E. A., I. M. Cheyne, and D. O. White. 1969. The structural proteins of Newcastle disease virus. Virology 39:118-129.

7. Homma, M. 1961. A particular binding of $L$ cell-grown Sendai virus by host $L$ cells (growth characteristics of myxoviruses in tissue culture, 5 th report). Tohoku $\mathrm{J}$. Exp. Med. 73:215-229.

8. Homma, M. 1971. Trypsin action on the growth of Sendai virus in tissue culture cells. I. Restoration of the infectivity for $L$ cells by direct action of trypsin on $L$ cell-borne Sendai virus. J. Virol. 8:619-629.

9. Homma, M. 1972. Trypsin action on the growth of Sendai virus in tissue culture cells. II. Restoration of the hemolytic activity of $\mathrm{L}$ cell-borne Sendai virus by trypsin. J. Virol. 9:829-835. 
10. Homma, M., and S. Tamagawa. 1973. Restoration of the fusion activity of $\mathrm{L}$ cell-borne Sendai virus by trypsin. J. Gen. Virol. 19:423-426.

11. Hosaka, Y. 1962. Characteristics of growth of HVJ in PS cells. Biken J. 5:121-125.

12. Hosaka, Y., and Y. K. Shimizu. 1972. Artificial assembly of envelope particles of HVJ (Sendai virus). I. Assembly of hemolytic and fusion factors from envelopes solubilized by Nonidet P40. Virology 49:627-639.

13. Iinuma, M., T. Yoshida, Y. Nagai, K. Maeno, T. Matsumoto, and M. Hoshino. 1971. Subunits of NDV. Hemagglutinin and neuraminidase subunits of Newcastle disease virus. Virology 46:663-677.

14. Ishida, N., and M. Homma. 1961. Host-controlled variation observed with Sendai virus grown in mouse fibroblast (L) cells. Virology 14:486-488.

15. Ito, Y., H. Okazaki, S. Sakuma, M. Homma, and N. Ishida. 1969. Specific requirement of serine for the growth of Newcastle disease virus. Virology 39:277-285.

16. Kashiwazaki, H., M. Homma, and N. Ishida. 1965. Assay of Sendai virus by immunofluorescence and hemadsorbed cell-counting procedures. Proc. Soc. Exp. Biol. Med. 120:134-138.

17. Kilbourne, E. D., P. W. Choppin, I. T. Schulze, C. Scholtissek, and D. L. Bucher. 1972. Influenza virus polypeptides and antigens. J. Infect. Dis. 125:447-455.

18. Klenk, H. D., and P. W. Choppin. 1969. Lipids of plasma membrane of monkey and human kidney cells and of parainfluenza virus grown in these cells. Virology 38:255-268

19. Klenk, H. D., and P. W. Choppin. 1970. Glycosphingolipids of plasma membranes of cultured cells and an enveloped virus (SV5) grown in these cells. Proc. Nat. Acad. Sci. U. S. A. 66:57-64.

20. Maeno, K., T. Yoshida, M. Iinuma, Y. Nagai, T. Matsumoto, and J. Asai. 1970. Isolation of hemagglutinin and neuraminidase subunits of hemagglutinating virus of Japan. J. Virol. 6:492-499.

21. Maizel, J. V., Jr. 1966. Acrylamide-gel electrophorograms by mechanical fractionation: radioactive adenovirus proteins. Science 151:988-990.

22. Matsumoto, T., and K. Maeno. 1962. A host-induced modification of hemagglutinating virus of Japan (HVJ, Sendai virus) in its hemolytic and cytopathic activity. Virology 17:563-570.

23. Mountcastle, W. E., R. W. Compans, L. A. Caliguiri, and P. W. Choppin. 1970. Nucleocapsid protein subunits of simian virus 5 , Newcastle disease virus, and Sendai virus. J. Virol. 6:677-684.

24. Mountcastle, W. E., R. W. Compans, and P. W. Choppin 1971. Proteins and glycoproteins of paramyxoviruses: a comparison of simian virus 5 , Newcastle disease virus, and Sendai virus. J. Virol. 7:47-52.

25. Scheid, A., L. A. Caliguiri, R. W. Compans, and P. W. Choppin. 1972. Isolation of paramyxovirus glycoproteins. Association of both hemagglutinating and neuraminidase activities with the larger SV5 glycoprotein. Virology 50:640-652.

26. Scheid, A., and P. W. Choppin. 1973. Isolation and purification of the envelope proteins of Newcastle disease virus. J. Virol. 11:263-271.

27. Shapiro, A. L., E. Vinuela, and J. V. Maizel. 1967. Molecular weight estimation of polypeptide chains by electrophoresis in SDS-polyacrylamide gel. Biochem. Biophys. Res. Commun. 28:815-820.

28. Shimizu, K., Y. Hosaka, and Y. K. Shimizu. 1972 Solubilization of envelopes of HVJ (Sendai virus) with alkali-emasol treatment and reassembly of envelope particles with removal of the detergent. J. Virol. 9:842-850.

29. Stenback, W. A., and D. P. Durand. 1963. Host influence on the density of Newcastle disease virus (NDV). Virology 20:545-551.

30. Young, N. P., and R. J. Ash. 1970. Polykaryocyte induction by Newcastle disease virus propagated on different hosts. J. Gen. Virol. 7:81-82.

31. Zacharius, R. M., T. E. Zell, J. H. Morisson, and J. J. Woodlock. 1969. Glycoprotein staining following electrophoresis on acrylamide gels. Anal. Biochem. 30:148-152. 